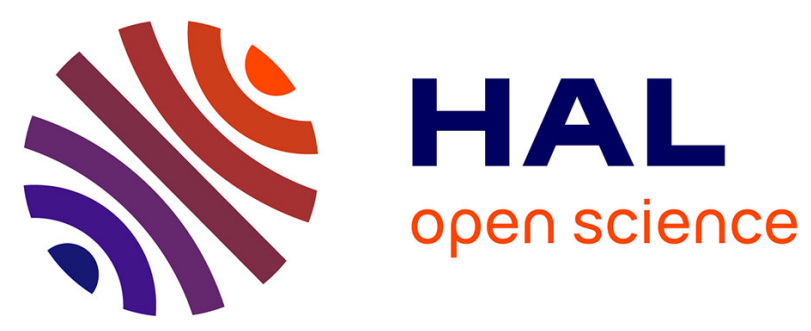

\title{
Local strain and damage measurements on a composite with digital image correlation and acoustic emission
}

Camille Flament, Michelle Salvia, Bruno Berthel, Gérard Crosland

\section{To cite this version:}

Camille Flament, Michelle Salvia, Bruno Berthel, Gérard Crosland. Local strain and damage measurements on a composite with digital image correlation and acoustic emission. Journal of Composite Materials, 2016, 50 (14), pp.1989-1996. 10.1177/0021998315597993 . hal-01522942

\section{HAL Id: hal-01522942 \\ https://hal.science/hal-01522942}

Submitted on 15 May 2017

HAL is a multi-disciplinary open access archive for the deposit and dissemination of scientific research documents, whether they are published or not. The documents may come from teaching and research institutions in France or abroad, or from public or private research centers.
L'archive ouverte pluridisciplinaire $\mathbf{H A L}$, est destinée au dépôt et à la diffusion de documents scientifiques de niveau recherche, publiés ou non, émanant des établissements d'enseignement et de recherche français ou étrangers, des laboratoires publics ou privés. 
C. Flament, M. Salvia, B. Berthel, G. Crosland, Journal of Composite Materials, 2016, 50, 1989.

\title{
Local strain and damage measurements on a composite with digital image correlation and acoustic emission
}

\section{Camille Flament $^{1,2}$, Michelle Salvia ${ }^{1}$, Bruno Berthel ${ }^{1}$ and Gérard Crosland ${ }^{2}$}

\begin{abstract}
Non linear stress-strain behaviour under monotonic loading can be caused by continuous damage. In order to understand this non linearity, simultaneous strain and damage measurements were taken on composite specimens using Digital Image Correlation (DIC) and Acoustic Emission (AE) as these techniques give valuable local information. The latter is essential in the case of inhomogeneous or anisotropic materials, such as continuous fibre composites. On the one hand, DIC gives access to full field strain and on the other hand, AE recording can be used for damage monitoring and location if, at least two sensors are placed on the specimen under loading. In this work these two techniques were combined to correlate strain measurements and damage location on a complex composite material during a monotonic tensile test. The composite is a continuous fibre reinforced friction material used in car clutches. These
\end{abstract}

\footnotetext{
${ }^{1}$ Laboratoire de Tribologie et Dynamique des Systèmes (LTDS), Ecole Centrale de Lyon, France

${ }^{2}$ VALEO Matériaux de friction, Rue Thimonnier, 87020 Limoges, France
}

\section{Corresponding author :}

Michelle Salvia, Ecole Centrale de Lyon, LTDS, UMR CNRS 5513, 69134 Ecully Cedex, France

Email : Michelle.Salvia@ec-lyon.fr 
measures were used to understand the non linearity of the stress-strain curve of the as received material as well as detect volume damage after thermal cycling. In depth study of the strain field and AE events location revealed a correlation between non homogeneous damage kinetics throughout the specimen and the evolution of the strain distribution.

\section{Keywords}

Composite material, digital image correlation, acoustic emission rate, damage location.

\section{Context}

To predict the behaviour of a structure, a good knowledge of the constitutive relations of each part is essential. To obtain the stress/strain relations strain measurements are conducted on simple mechanical tests. For certain materials, the stress-strain curve may be non linear. Damage is one of the causes of non linearity in the stress/strain curve. To identify such a behaviour strain and damage must be measured simultaneously. To measure strain many techniques can be used (extensometers, strain gauges, ..), however, when working with inhomogeneous or anisotropic materials, such as continuous fibre composites, accurate strain measurements call for full field data. Amongst the different full field measurement techniques, Digital Image Correlation (DIC) is one of the most popular ${ }^{1-6}$. It is an optic contactless experimental technique to measure full field displacements and strain with sub-pixel accuracy. Failure mechanisms can be identified with different non destructive techniques such as Acoustic Emission (AE) recording which can be used for damage monitoring ${ }^{7-12}$. In fact elastic waves are emitted as a consequence of crack initiation and propagation. Therefore analysing the acoustic activity gives information on the type of damage that occurs in the material ${ }^{13,14}$. Furthermore, if at least two sensors are 
placed on the specimen under loading, and the wave propagation velocity is known, location of each acoustic event is possible ${ }^{15}$.

The aim of this work is to combine these two techniques to correlate strain measurements and damage location during a monotonic tensile test and determine if the non-linearity of the stress-strain curve is due to volume damage. Damage location will also be compared with strain distribution. In addition, as car clutches are submitted to thermal cycling, volume damage resulting in reduced strength was characterised on thermally cycled specimens using AE signals emitted during a monotonic tensile test.

\section{Material and loading}

The material studied is the organic clutch facing that transmits the rotary motion between the engine and the wheels. It is an annular shaped continuous fibre composite constituted by a fibre glass yarn fitted with copper strips. The studied clutch facing has external and internal diameters of 240 and $160 \mathrm{~mm}$ respectively. The composite matrix is mainly composed of a phenolic thermosetting resin. The steps of the process of fabrication are described by Bezzazi and Khamlichi ${ }^{16}$. During the preforming operation, a machine guides the impregnated fibres coupling a uniform rotation with a radial translation. The two movements have different frequencies resulting in a fibre organisation such as presented Figure 1. The number of sin wave per $2 \pi$ phase angle $(\mathrm{N})$ is an important parameter as it defines the fibre orientation ${ }^{17}$. The preform is put into a heated mould pressed and cured at $250^{\circ} \mathrm{C}$. The fibre organisation confers an orthotropic behaviour to the material. The orthotropic axes are the radial and the tangential axes ${ }^{18}$. In this paper only mechanical properties in the tangential direction were studied. Rectangular specimens (120x20x1.8) were cut into the disc to perform the tensile tests as shown Figure 1. 

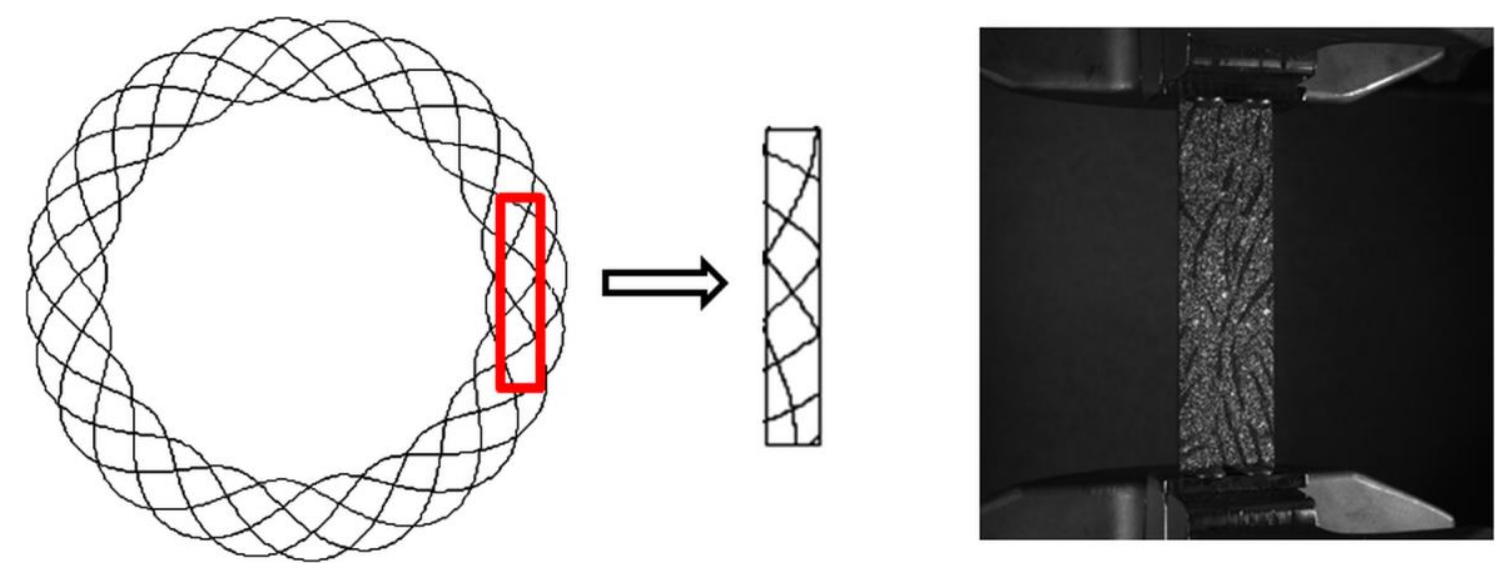

Figure 1. Preform and view of the rectangular specimen cut into the disc.

\section{Experimental Techniques}

\section{Digital Image Correlation}

The digital image correlation (DIC) technique provides displacements and strain maps on deformed surfaces. The correlation is possible only if the surface has a random texture, such as a black and white speckle. The surface is often painted with black and white spray paint. A region of interest (ROI) is defined on the specimen surface. The ROI is divided into subsets which are tracked by the algorithm 

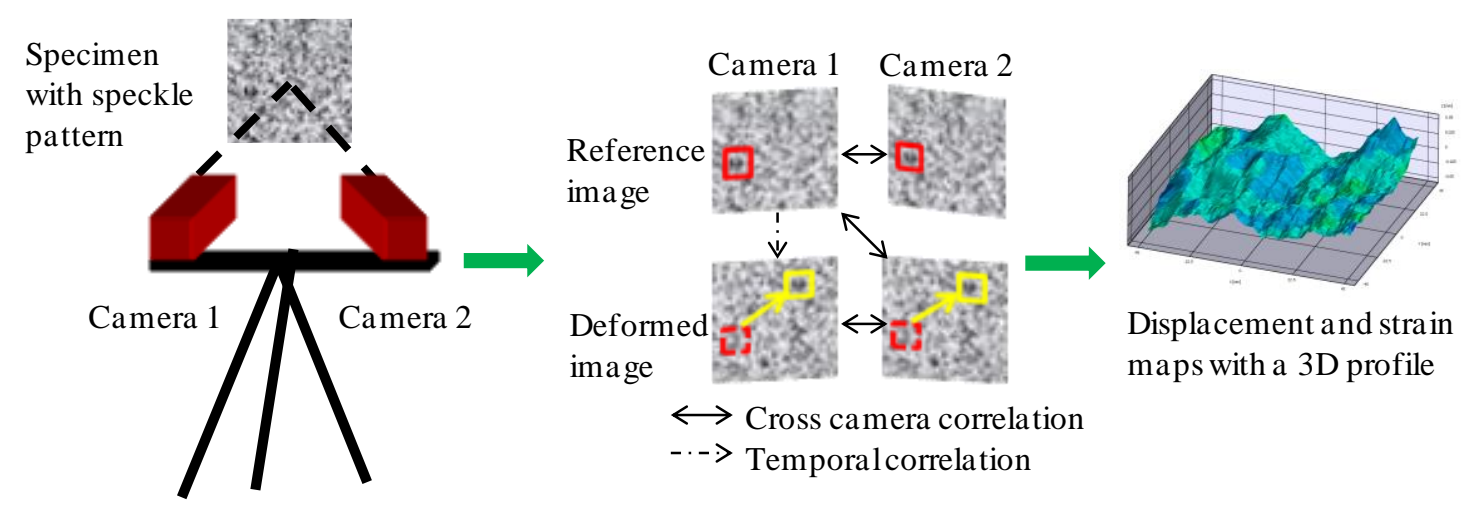

Figure 2. Schematic view of the process of DISC.

which finds the corresponding location of the reference subsets in the deformed image. To compare the deformed and reference subsets, the DIC algorithm compares the grey level of each pixel in each subset. Once the matching is done, the displacement components of the centre of the reference and deformed subset can be determined. The strain field is then derived from the filtered displacement field ${ }^{19}$. When using one camera, (2D-DIC), the temporal correlation as described above does not take into account out of plane displacements. To determine the position of an object in the three dimensions, two simultaneous images of the same object, with a different camera angle are needed. Digital image stereo correlation (DISC or 3D-DIC) combines temporal and stereoscopic matching (Figure 2). The DISC method makes the difference between strain and out of plain displacements and gives access to $3 \mathrm{D}$ profiles. In order to correlate the stereo-images, the correlation algorithm needs information on the orientation and position parameters of the cameras as well as the intrinsic parameters of each camera. These parameters are determined by calibrating the stereo-vision set up which is done by recording images of a calibration target. The system used in our laboratory is Vic 3D developed by Correlated Solutions ${ }^{20}$. 
C. Flament, M. Salvia, B. Berthel, G. Crosland, Journal of Composite Materials, 2016, 50, 1989.

\section{Acoustic emission : accuracy of location}

Acoustic emission (AE) signals were acquired and processed with the $\mathrm{AE}$ acquisition and analysing system AEwin for Mistras of Physical Acoustics Corp. The AE signals during the tests were detected by two piezoelectric sensors (type R15) attached to the sample by a silicon grease and clips. The threshold of the $\mathrm{AE}$ system was set to $35 \mathrm{~dB}$, any event with a lower amplitude was not detected. To test the accuracy of the $\mathrm{AE}$ system when locating events, $100 \mathrm{~dB}$ events were generated on a marked specimen using pencil lead break. The AE location map was then compared to the known location of the events. Two sources of errors have been identified : the velocity uncertainty and the repeatability of the acquisition system. The wave velocity of our specimens is $2770+/-140 \mathrm{~m} / \mathrm{s}$. Here, this uncertainty corresponds to a variability in the location of $+/-1 \mathrm{~mm}$. The repeatability was also tested and that gave an uncertainty of $+/-1.9 \mathrm{~mm}$. These two tests give an overall confidence interval of $5 \mathrm{~mm}$ on the location accuracy of our system.

\section{Experimental set up}

Specimens were cut into the annular disc in the tangential direction. The dimensions of the loaded area were $80 \times 20 \times 1.8 \mathrm{~mm}$. The tensile loading was performed at an imposed displacement rate of $1 \mathrm{~mm} / \mathrm{min}$ until the complete failure of the specimen. During the test the load, the strain field and the acoustic emission signals were recorded. The two sensors were placed at each end of the specimen, $70 \mathrm{~mm}$ from each other. The wave velocity was measured for each specimen prior to testing using a pencil break test. The outline of the experimental set up is shown Figure 3. 


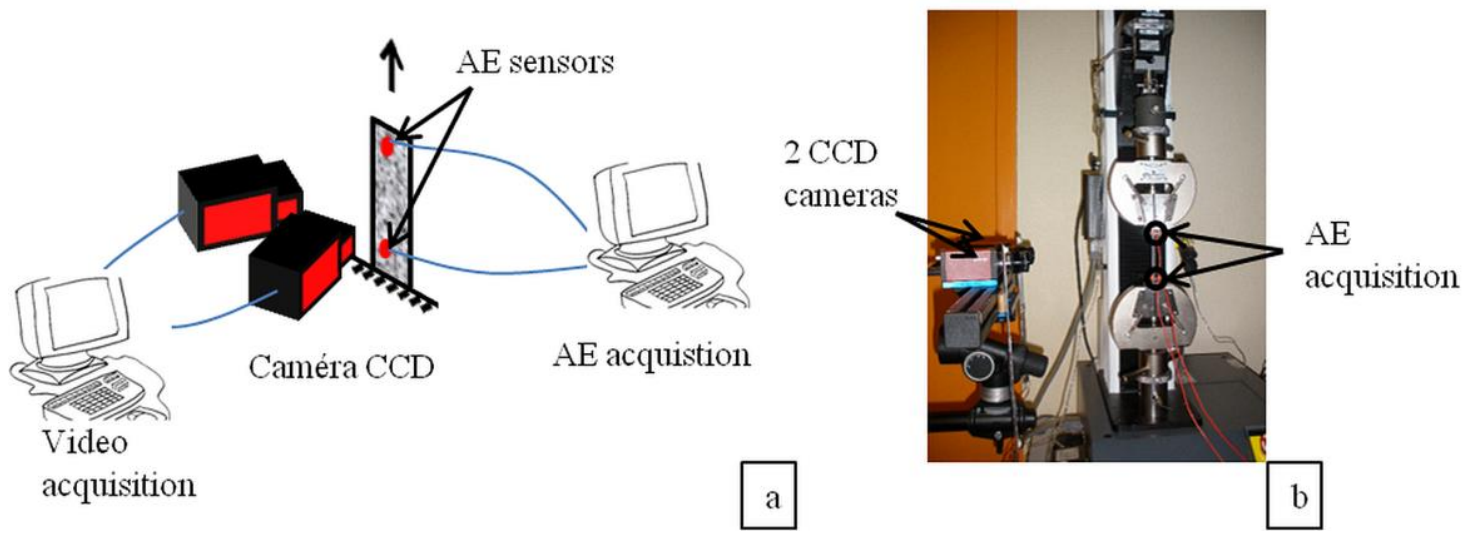

Figure 3. Outline of the experimental set up (a) and photo (b).

\section{Results}

\section{Acoustic emission signals versus load}

Three as-received specimens were tested using this experimental set up. Figure 4.a and b presents the results obtained on one specimen. The other two showed the same behaviour with the same type of events in each phase and the same absolute value of stress at the transition from phase 1 to 2 .

AE signals are detected very early in the test under $10 \%$ of the maximum load and until the specimen fails. In the first phase (1), up to $60 \%$ of the maximum stress, many events of small amplitude and low energy occur (Figure 4 (a)). These events are often related to matrix cracking ${ }^{7}$. In the second phase, events over $80 \mathrm{~dB}$ and high energy are measured. These events are linked to fibre break ${ }^{13}$. Low to average amplitude and energy events still occur in this phase. These aspects combined could indicate friction due to fibre/matrix debonding ${ }^{11,13,21}$. The third phase is when failure occurs : multiple high energy and high amplitude events indicate multiple fibre breakage ${ }^{13}$. In the same time, numerous events of lower 
amplitude are a sign of important matrix cracking. In this phase the material fails. The continuous damage recorded during the test could explain the non linearity of the stress-strain curve.

In addition to a change in the type of events occurring in phase 1 and 2 there is a drastic change in the $\mathrm{AE}$ emission rate (Figure 4(b)). In the first phase, it increases drastically it is a phase uncontrolled flaw growth $^{15}$. Then, over a load of $60 \%$ of the maximum load the AE rate is constant and around 100 events per second, the flaw growth is controlled ${ }^{15}$. It seems as if in the first phase there is a rapid relaxation of the internal constraints before reaching a steady state where the flaw growth is constant. This kinematic is independent of the type of damage (amplitude $<85 \mathrm{~dB}$ ) and, as we will see in the next paragraph, of its location. This kinetic has been observed, for example, by Henrat and al. as well as O.Ceysson on cross plied composites under monotonic tests ${ }^{11,22}$. This change in damage mechanisms is not visible on the stress curve.

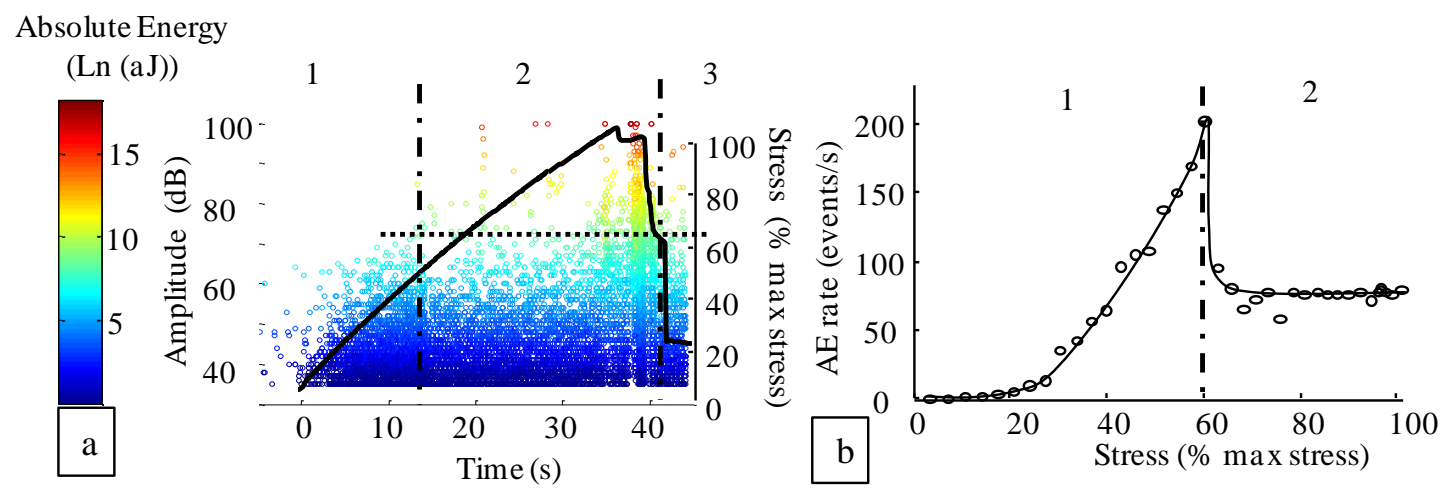

Figure 4. (a) Amplitude and energy of the AE signals and stress curve. (b) AE rate versus stress. 


\section{Location}

The simultaneous DIC and AE measurements give local information on strain and local damage. The outline and the photo presented on Figure 5 show the relative position of the two AE sensors and the region of interest (ROI) where the strain field was measured. The load was applied in the Y direction. To match the coordinate system of the acoustic emission location and the strain field, the coordinates of the crack were used : the maximum strain was matched with the crack location. The same repositioning was applied to the AE histogram : the maximum number of events was matched with the crack coordinates. Considering the location accuracy and the repositioning of each coordinate system, the AE events were counted on $5 \mathrm{~mm}$ strips, every five millimetres (no overlap).
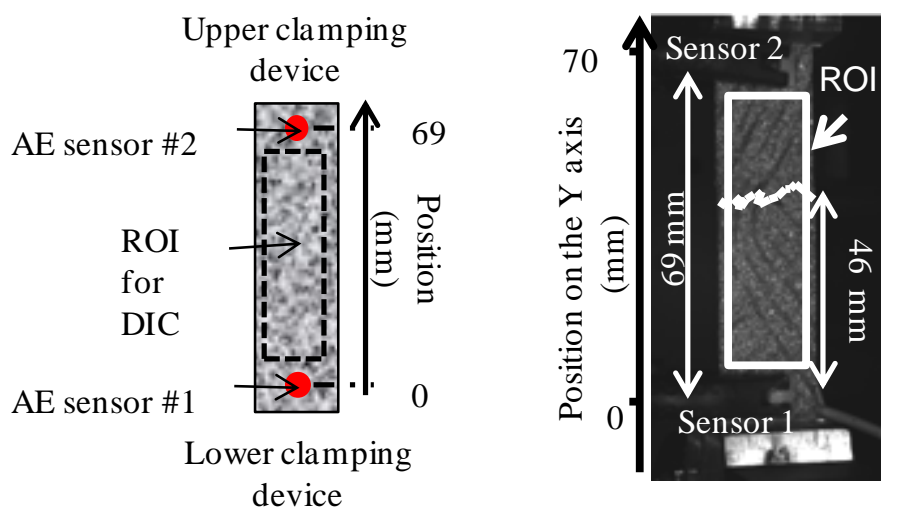

Figure 5. Position of the two AE sensors and the region of interest (ROI).

The comparison between local cumulated number of events and the strain distribution was correlated for each zone one, two and three. In Figure 6-8 (a), the events were counted and plotted versus time for every Y position on the specimen (strip width for counting is $5 \mathrm{~mm}$ ). The strain distribution for each time $\mathrm{t} 1$, $\mathrm{t} 2$ and $t 3$ is shown on Figure 6-8 (b). Three types of damage kinetics can be identified (Figure 6-8). The analysis is shown here for one as-received specimen 
C. Flament, M. Salvia, B. Berthel, G. Crosland, Journal of Composite Materials, 2016, 50, 1989.

Type A (Figure 6) : increase in the number of events in phase one followed by a stabilisation (Figure 6 (a)). There are scarcely any new crack initiation or propagation in phase two. This kind of damage kinetics occur in low strain areas on the specimen (Figure $6(\mathrm{~b})$ ).
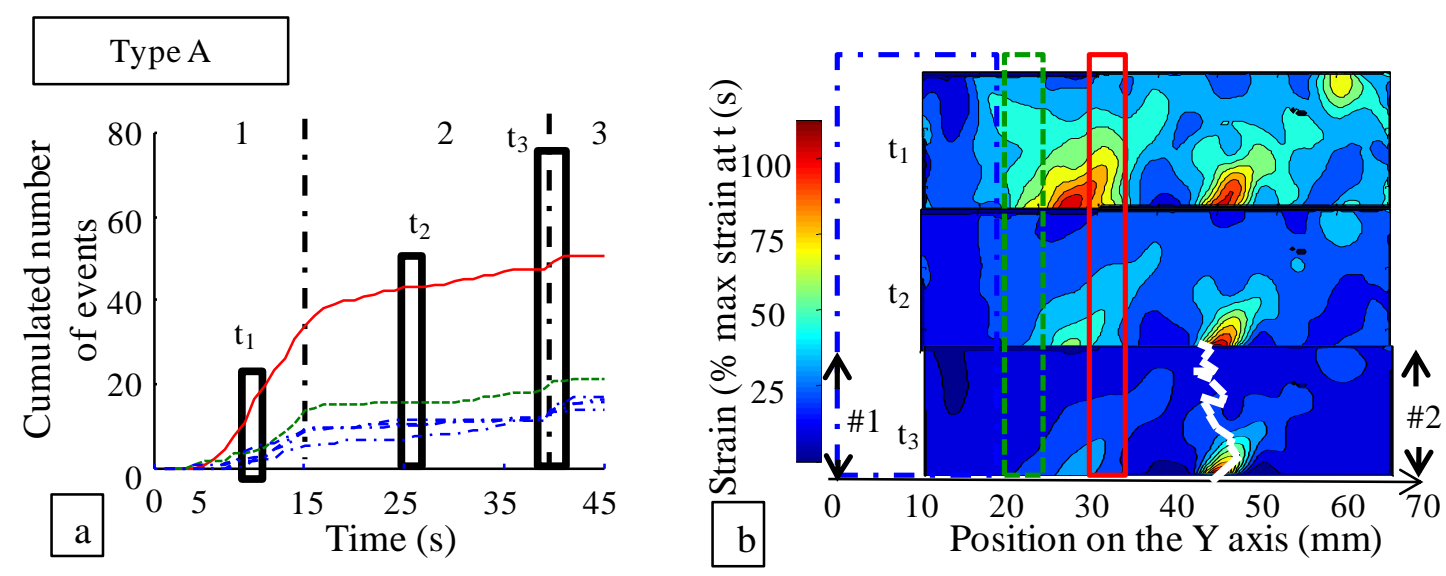

Figure 6. Type A damage kinetics (a) cumulated number of events versus time for different Y positions.

(b) strain distribution, between AE sensor \#1 and \#2, at t1, t2 and t 3 with the circled corresponding Y position of type A damage kinetics.

Type B (Figure 7): exponential increase of the number of events in phase one followed by a linear increase in phase two with a moderate slope $(0.57$ events/s) visible on Figure 7 (a). This kind of damage kinetics corresponds to hot spots that appear at the beginning of the tensile test then fade away (Figure 7 (b)). 

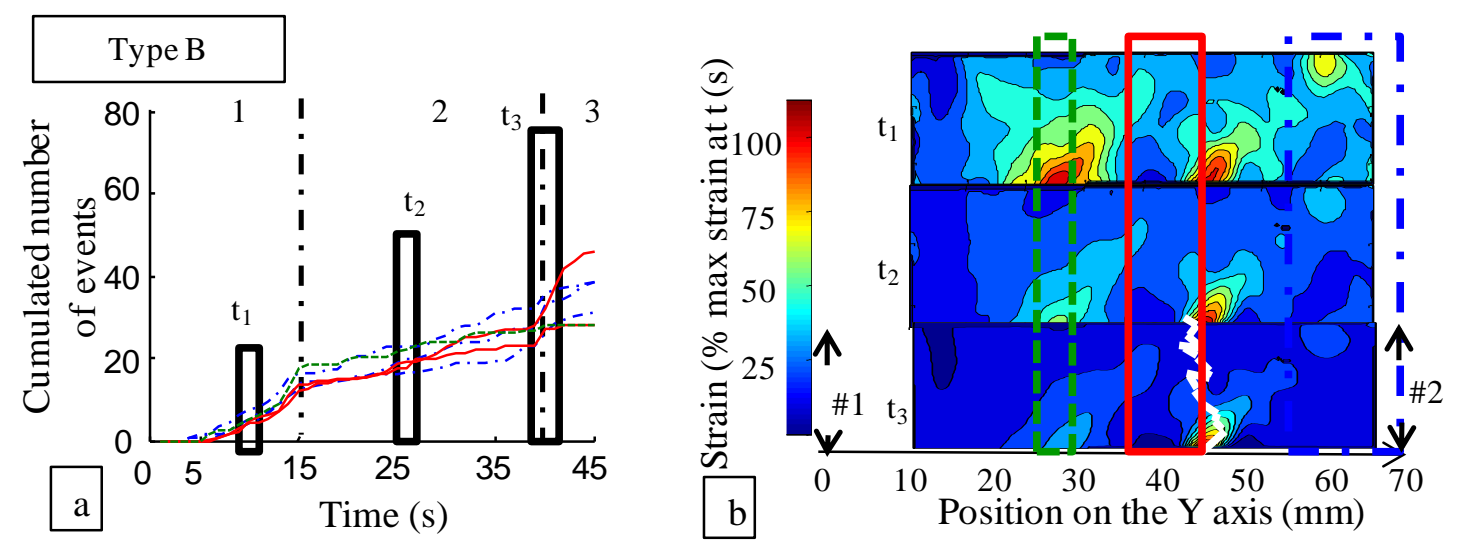

Figure 7. Type B damage kinetics (a) cumulated number of events versus time for different Y positions.

(b) strain distribution at $\mathrm{t} 1, \mathrm{t} 2$ and $\mathrm{t} 3$, between $\mathrm{AE}$ sensor \#1 and \#2, with the circled corresponding $\mathrm{Y}$ position of type B damage kinetics.

Type C (Figure 8): exponential increase of the number of events in phase one followed by a linear increase in phase two with a twice as important slope as type B ( 1.1 events/s) visible in Figure 8 (a). In phase three the final increase of the number of events leads to the failure of the specimen. This kind of damage kinetics is found in the area where the strain is maximum throughout the test which is also the position where failure occurs (Figure 8 (b)).
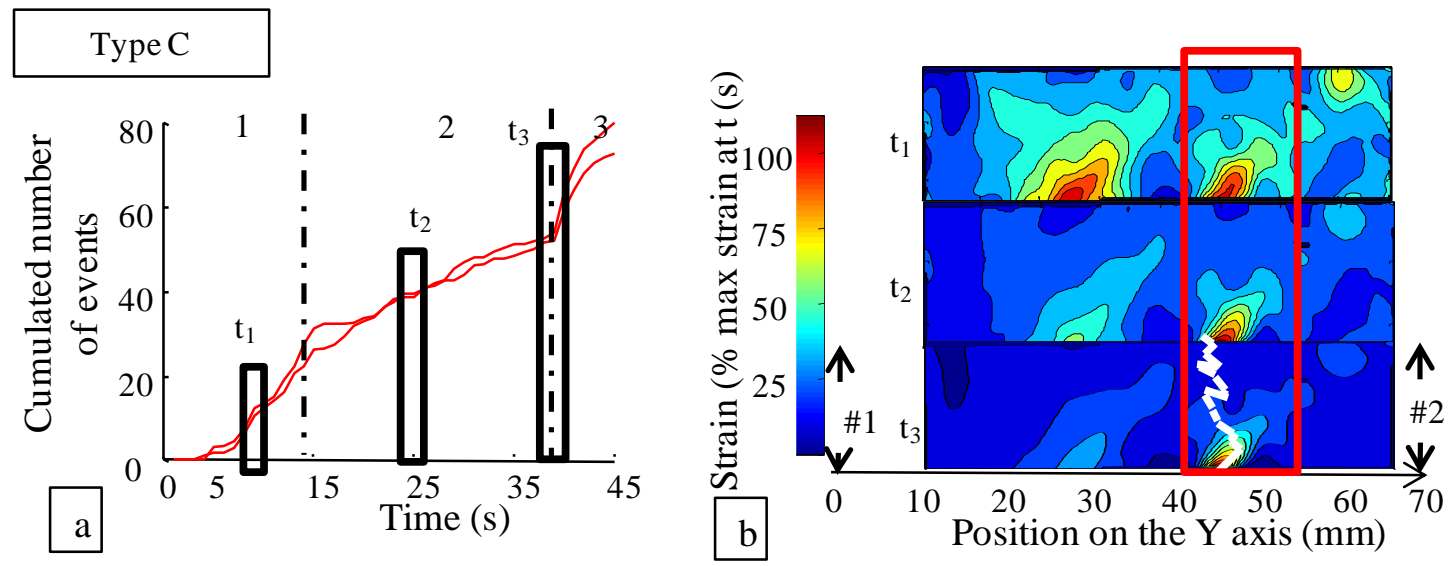
Figure 8. Type $\mathrm{C}$ damage kinetics (a) cumulated number of events versus time for different $\mathrm{Y}$ positions.

(b) strain distribution at $\mathrm{t} 1, \mathrm{t} 2$ and $\mathrm{t} 3$, between $\mathrm{AE}$ sensor \#1 and \#2, with the circled corresponding $\mathrm{Y}$ position of type $\mathrm{C}$ damage kinetics.

As specified before, this analysis was conducted on one as-received specimen. The other two show the same patterns with the failure initiating in zones presenting type $\mathrm{C}$ damage kinetics.

The damage kinetics is non homogenously distributed in the specimen and the distribution is related to the local strain evolution during the tensile test. This distribution is related to the non homogeneous fibre organisation as shown figure 1 as the angle between the traction direction and local fibre orientation is not the same throughout the specimen. Figure 9 presents the histogram of the cumulated events and the strain map at the end of the tensile test when the specimen fails. On the histogram (top of Figure 9) a higher number of events occurs around $30-35 \mathrm{~mm}$ and $40-50 \mathrm{~mm}$. These two regions correspond to two high strain areas in the strain field. These high strain zones are in fact strips oriented at around $45^{\circ}$ from the loading axis which coincides with the fibre organisation ${ }^{18}$.

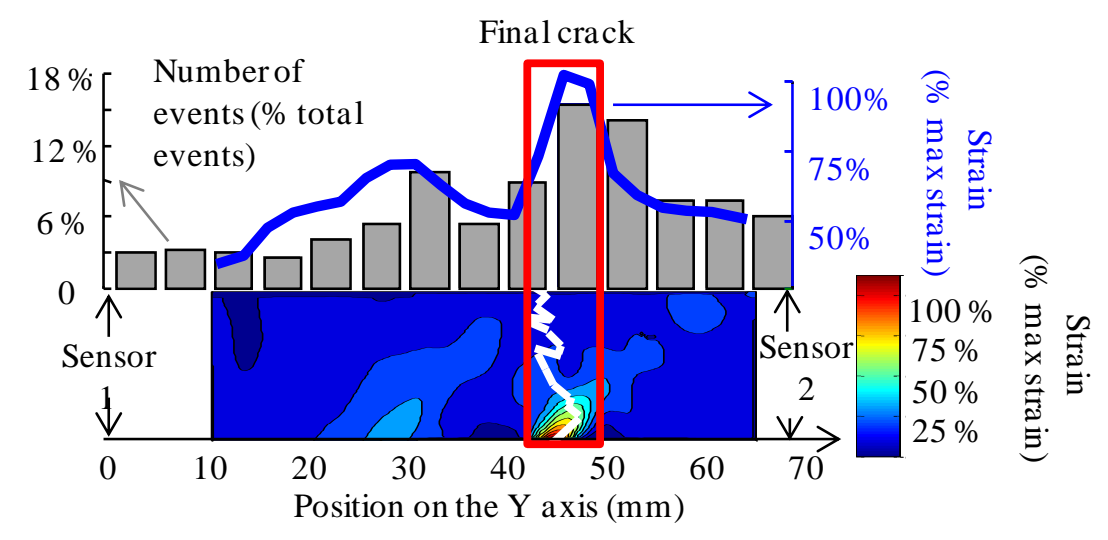

Figure 9. Cumulative number of acoustic events and strain field prior to failure. 


\section{Effect of thermal cycling}

During the engagement manoeuvre, sliding contact occurs between the clutch facing and the counter faces (flywheel or pressure plate) which increases the material temperature. The temperature rise can be important in the case of repetitive engagement. The thermal loading is cyclic as the clutch is engaged and disengaged many times during its life cycle. Thermal cycling can cause volume damage and a good knowledge of these phenomena is necessary to guarantee life expandency. To identify and quantify this degradation mechanism, specimens were submitted to 6 thermal cycles, described in Figure 10, with a maximum temperature of $200^{\circ} \mathrm{C}$ or $300^{\circ} \mathrm{C}$. The specimens were then tested with the same monotonic tensile test at ambient temperature as described in part 3.3. Strain fields and AE signals were measured.

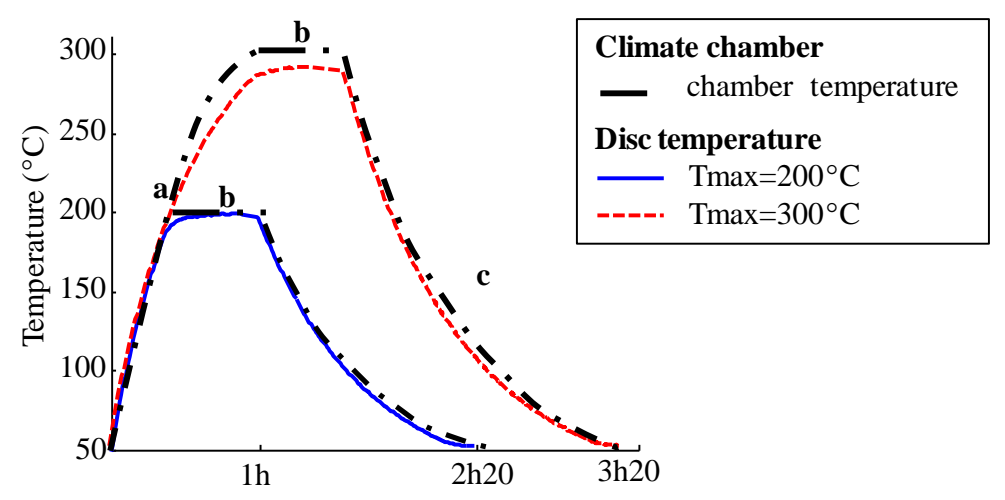

\begin{tabular}{|l|}
\hline $\mathrm{a}:$ ramp $8^{\circ} \mathrm{C} / \mathrm{min}$ \\
\hline $\mathrm{b}:$ plateau \\
\hline $\mathrm{c}:$ free cooling \\
\hline
\end{tabular}

Figure 10. Thermal cycles

AE signals for the two cycled specimens are shown Figure 11. The phases one, two and three have been identified with the same criteria as part 4.1, based on the AE rate and the discontinuities of the stress curve. When cycled at $200^{\circ} \mathrm{C}$ the specimen has the same ultimate strength but different $\mathrm{AE}$ signals. The shift from phase 1 to 2 happens at half the load of the as received one ( $45 \%$ max stress of the as received material). Furthermore acoustic events of high energy and high amplitude are measured for a very low 
load, including $100 \mathrm{~dB}$ events. In the same way, high amplitude events happen early in the test for the specimen cycled at $300^{\circ} \mathrm{C}$ and the shift from phase one to two happens at $35 \%$ of the maximum load compared to $60 \%$ in the case of the as received material. However the second phase is shorter and the shift from phase 2 to phase three appears at $50 \%$ max stress of the as received material. In phase three there is a progressive damage of the specimen and many discontinuities appear on the stress curve. Fibres break when $20 \%$ of the maximum load of the as received material is reached and the ultimate strength is reduced by $30 \%$ compared to the as received material. The aged specimens present AE signals which show that damage initiation and propagation in a thermally cycled material is different from the asreceived material. This evolution is a sign of damage creation and weakening of the matrix and the fibres caused by thermal cycling. There are more fibre break in the $300^{\circ} \mathrm{C}$ cycled specimen.
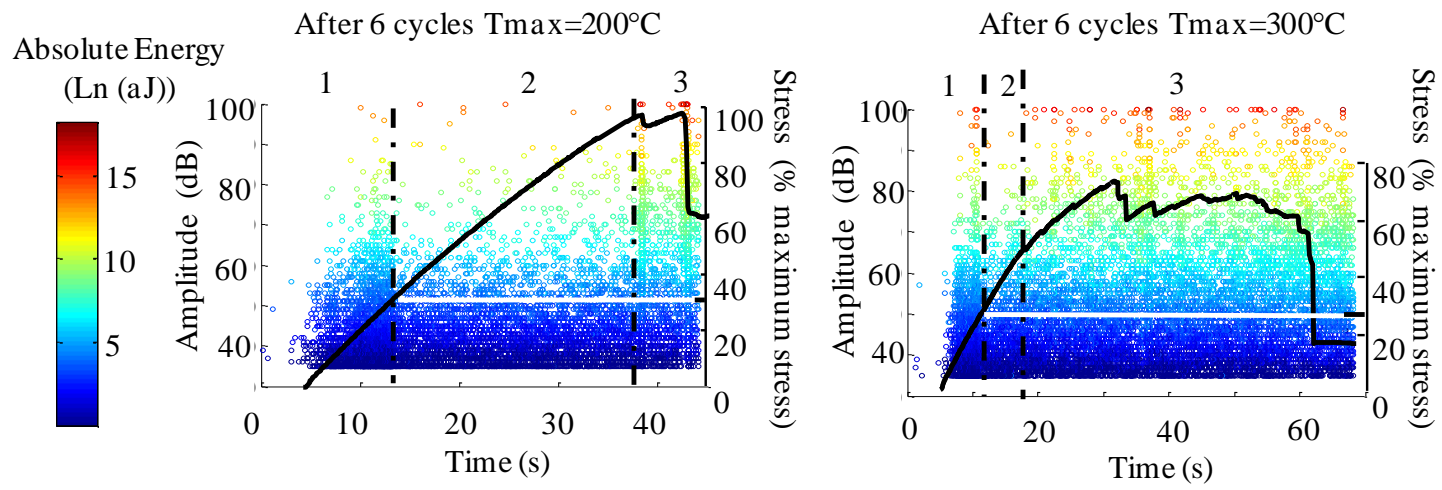

Figure 11. Amplitude and energy of the AE signals with the stress curve of the $200^{\circ} \mathrm{C}$ and $300^{\circ} \mathrm{C}$ cycled specimens respectively.

The AE rate versus maximum stress is shown Figure 12. Whether the specimen has been thermally cycled or not does not change the aspect of the curve, however the stress at which the damage kinetics goes from uncontrolled to controlled flaw growth decreases with increasing temperature of the thermal cycles. This 
could be an indication of higher existing damage prior to tensile testing due to thermal cycling. However, it has no impact on the ultimate strength after 6 cycles at $200^{\circ} \mathrm{C}$.

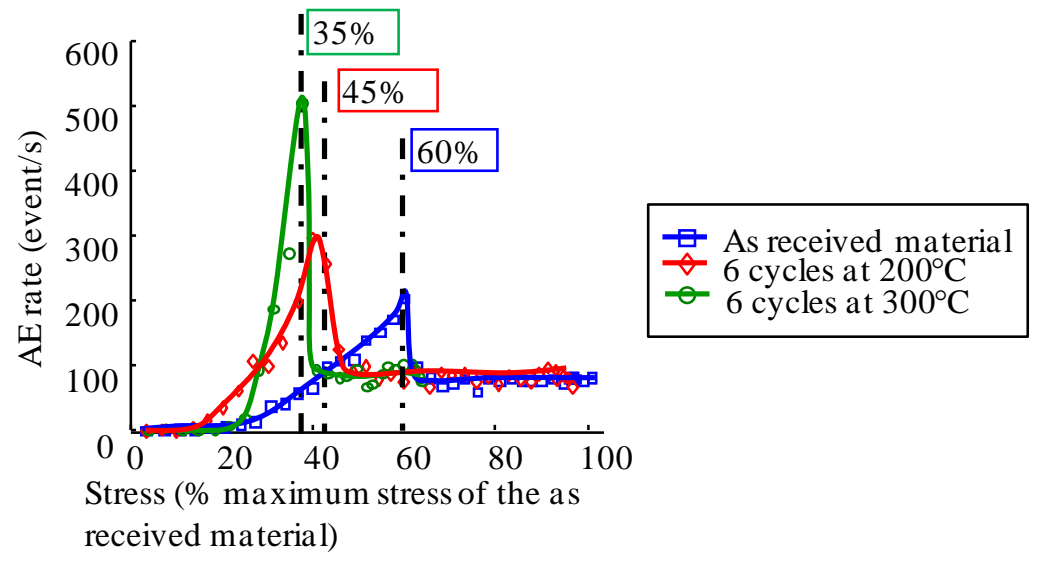

Figure 12. Acoustic emission rate versus stress for the as received and thermally cycled material.

These results give an information on the volume degradation which completes previous results on the damage mechanisms occurring on a thermally cycled clutch facing where surface cracking was observed $^{23}$. Macroscopic cracks were found on the surface of the $300^{\circ} \mathrm{C}$ cycled specimens, however nothing was visible, at that scale, on the $200^{\circ} \mathrm{C}$ cycled. The additional information given by AE signals as a damage monitoring technique has highlighted the fact that $200^{\circ} \mathrm{C}$ cycled specimen are affected by thermal cycling.

Thermally cycled specimen present signs of damage for a very low number of cycles. However, it is important to bear in mind that the specimens are subjected to homogeneous and slow thermal cycles which is severe compared to the actual one-sided fast heating due to friction. Therefore, further investigations are needed to transpose these results to the performance of the clutch facing. In addition, in everyday use, the temperature of the studied clutch facing is seldom over $200^{\circ} \mathrm{C}$. 


\section{Conclusions}

The aim of this work was to have a better understanding of the non-linearity of the stress-strain curve of the composite used in car clutch facings. Simultaneous measures of the strain field, using DIC, and damage location, using AE, were done on a rectangular specimen under monotonic tensile loading. Local strain was then compared to local damage. The correlation between strain fields and AE location is possible providing correct use of the coordinate systems. It was found that maxima in the strain field correspond to increased local AE activity. Furthermore, a comparison of the local cumulated number of events and strain distribution revealed that the the damage kinetics is non homogenously distributed in the specimen and the distribution is related to the local strain evolution during the tensile test. Continuous damage was recorded during the test which could explain the non-linearity of the stress-strain curve. Furthermore AE signals were use to detect volume damage on specimens that were thermally cycled at $200^{\circ} \mathrm{C}$ or $300^{\circ} \mathrm{C}$. After 6 cycles, the specimens were tested under monotonic tensile load with AE sensors detecting AE signals. These measures revealed volume damage of the $200^{\circ} \mathrm{C}$ cycled specimens that was neither visible on the stress-strain curve nor on the surface of the specimen.

\section{References}

1. Goidescu C, Welemane H, Garnier C, Fazzini M, Brault R, Péronnet E, et al. Composites : Part B Damage investigation in CFRP composites using full-field measurement techniques: Combination of digital image stereo-correlation, infrared thermography and X-ray tomography. Compos Part B. 2013; 48:95-105.

2. Haldar S, Gheewala N, Grande-Allen KJ, Sutton M a., Bruck H a. Multi-scale Mechanical Characterization of Palmetto Wood using Digital Image Correlation to Develop a Template for Biologically-Inspired Polymer Composites. Exp Mech. 2010 ;51(4):575-589.

3. Leplay P, Réthoré J, Meille S, Baietto M-C. Identification of asymmetric constitutive laws at high temperature based on Digital Image Correlation. J Eur Ceram Soc. 2012;32(15):3949-3958.

4. Jerabek M, Major Z, Lang RW. Strain determination of polymeric materials using digital image correlation. Polym Test. 2010;29(3):407-416. 
5. Eitner U, Köntges M, Brendel R. Use of digital image correlation technique to determine thermomechanical deformations in photovoltaic laminates: Measurements and accuracy. Sol Energy Mater Sol Cells. 2010 ;94(8):1346-1351.

6. Robert L, Nazaret F, Cutard T, Orteu J-J. Use of 3-D Digital Image Correlation to Characterize the Mechanical Behavior of a Fiber Reinforced Refractory Castable. Exp Mech. 2007;47(6):761773.

7. Barre S, Benzeggagh ML. On the use of acoustic emission to investigate damage mechanisms in glass-fibre-reinforced polypropylene. Compos Sci Technol. 1994;52:369-376.

8. Quispitupa A, Shafiq B, Just F, Serrano D. Acoustic emission based tensile characteristics of sandwich composites. Compos Part B Eng. 2004; 35(6-8):563-571.

9. Albouy $\mathrm{W}$, Vieille B. Determination of the damage threshold in woven-ply thermoplastic laminates at T>Tg: Acoustic emission and microscopic damage analysis. Compos Part B Eng. $2014 ; 64: 138-146$.

10. Loutas T, Kostopoulos V. Health monitoring of carbon/carbon, woven reinforced composites. Damage assessment by using advanced signal processing techniques. Part I: Acoustic emission monitoring and damage mechanisms evolution. Compos Sci Technol. 2009 ;69(2):265-272.

11. Ceysson O. Caracterisation du comportement en fluage de materiaux compoistes carbone/epoxyde étude de l'endommagement. Thesis Ecole Centrale de Lyon, France, 1996;

12. Farhidzadeh a., Salamone S, Luna B, Whittaker a. Acoustic emission monitoring of a reinforced concrete shear wall by b-value-based outlier analysis. Struct Heal Monit. 2012 ;12(1):3-13.

13. Mechraoui S-E, Laksimi A, Benmedakhene S. Reliability of damage mechanism localisation by acoustic emission on glass/epoxy composite material plate. Compos Struct. 2 ;94(5):1483-1494.

14. Pollock AA. Acoustic emission -2 Acoustic emission amplitudes. Non-Destructive Test. 1973;(October):264-269.

15. Beattie AG. Acoustic Emission Non-Destructive Testing of Structures using Source Location Techniques. 2013.

16. Bezzazi M, Khamlichi A. Experimental characterization of frictional behaviour of clutch facings using Pin-on-disk machine. Mater Des. 2007;28:2148-2153.

17. Karadeniz ZH, Kumlutas D. A numerical study on the coefficients of thermal expansion of fiber reinforced composite materials. Compos strucutres. 2007;78:1-10.

18. Flament C, Salvia M, Berthel B, Crosland G. Digital image correlation applied to thermal expansion of composites. In: ICCM. 2013. p. 5235-5243.

19. Sutton MA, Orteu JJ, Shreier HW. Image Correlation for Shape Motion and Deformation Measurements. Basic Concepts, Theory and Application. 1st Editio. Springer US; 2009.

20. Correlated Solutions.Inc [Internet]. Available from: http://www.correlatedsolutions.com/

21. Karger-Koscsis J, Harmia T, Czighany T. Comparison of the fracture and failure behavior of the polypropylene composites reinforced by long glass fibers and by glass mats. Compos Sci Technol. 1995;54:287-298.

22. Henrat P, Vautrin a., Harris B. Mechanical and acoustic emission response of unidirectional and cross-plied GRP laminates. Compos Sci Technol. 1987;30:263-277. 
C. Flament, M. Salvia, B. Berthel, G. Crosland, Journal of Composite Materials, 2016, 50, 1989.

23. Flament C;, Salvia M;, Berthel B;, Crosland G. Effect of thermal cycling on the mechanical properties of a continuous fibre composite used for car clutch facings. In: Fatigue 2014. 2014. p. $42-47$. 